\title{
Experimental and Theoretical Study on Characteristics of Pulse Excitation in T-Burners
}

\author{
Mi Yan ${ }^{\mathrm{a}}$, Ningfei Wang ${ }^{\mathrm{a}}$, Junwei $\mathrm{Li}^{\mathrm{a},}$, , Anchen Song ${ }^{\mathrm{a}}$, Yu Ma ${ }^{\mathrm{b}}$ \\ ${ }^{a}$ Beijing institute of technology, Beijing, 100081, China \\ ${ }^{\mathrm{b}}$ Xi'an Modern Chemistry Research Institute, Xi'an, Shanxi, 710065, China
}

Pulse excitation is the key to measure the pressure-coupling response function of composite propellant. It is also a key trigger factor for nonlinear combustion instability. This paper aims at understanding characteristics of pulse excitation in T-burners. Pulse excitation is provided by black powder (BP). $\mathrm{D}^{2}$ law is used to calculate BP burning properties. Firstly, the experimental pressure history of a pulse excitation is analyzed. Pressure pulse and mean pressure increment are introduced to describe pulse excitation. Secondly, the modified zero-dimension model and one-dimension model of pressure pulse are established based on energy conservation and modification. The results of models indicate that the modified zero-dimensional model can accurately predict the pressure pulse. The modified zero-dimension model demonstrates that the pressure pulse is determined by pulse build-up time threshold, volume coefficient, effective weight fraction of BP, weight of BP et. al. When burning time of BP is larger than the threshold, volume coefficient is equal to 2 , and effective weight fraction of $\mathrm{BP}$ is less than 1 . The pressure pulse is approximately linear correlation with weight and effective weight fraction of BP. Otherwise, volume coefficient is larger than 2 , and effective weight fraction of BP is equal to 1 . The pressure pulse is approximately linear correlation with volume coefficient and BP weight. Thirdly, a zero-dimensional prediction model of mean pressure is established based on conservations of energy and mass. The prediction models of pressure pulse and mean pressure are validated by T-burner experiments. Finally, effects of BP burning properties on pressure pulse and mean pressure increment are studied. The results show that both pressure pulse and mean pressure increment increase with increasing BP weight, linearly. The pressure pulse is more sensitivity to the variations of burning time of BP. As burning time of BP decreases, the mean pressure increment gradually increases to the maximum, and the pressure pulse can become a very large value.

Keywords: T-burner, pulse excitation, black powder, pressure pulse, mean pressure increment

\footnotetext{
* Corresponding author. E-mail address: david781ee@gmail.com.
} 


\section{Introduction}

Combustion instability is a thorny problem in motors [1-3]. Its fundamental characteristics are the periodic oscillations of pressure, burning rate and thrust [4]. For a solid rocket, the oscillations in motors could be induced by complex mechanisms, such as pressure-coupled response [5], vortex-acoustic coupling [6], distributed combustion [7], et al. Combustion instability typically includes linear state and nonlinear state. A linear stable motor can be translated to the nonlinearly unstable when it is triggered by pulse $[8,9]$. In order to investigate nonlinear combustion instability of rocket motors, pulse excitation technology is employed in various experiments for decades [10-13]. Except for damping and gain of the combustion chamber, the most important factor is the intensity of pulsed excitation, which determines whether nonlinear combustion instability can be triggered [14]. In addition, pulse excitation is also an important way to measure the pressure-coupled response of composite propellant in T-burners [5, 15-17]. The pressure-coupled response function is a function of pressure and frequency [1]. Pressure pulse of pulse excitation determines whether the pressure oscillation in T-burner can be triggered successfully. It also determines the frequency distribution of the pressure oscillation [11]. Mean pressure increment of pulse excitation determines the accuracy of the experimental measurement of pressure-coupled response [18]. Therefore, pulse excitation is required to be controllable and reliable. It is needed to study the characteristics of pulse excitation in detail.

As the first step of pulse model development, Murray $[19,20]$ put forward a series of pulse sources which are pyrotechnic, low brisance, ejecta and piston. Then details of pulse model were researched by Baum, et al. [21-24], who pointed out the relationship between pulser performances and pulse sources. It can be concluded from Ref. [21] that pulse sources had little effects on pulse peak. And the characteristics 
of pulse, such as amplitude, pulse release time were determined by mass flow rate and energy flow rate of pulser. In the research of cold-flow testing for piston pulser and pyrotechnic pulser in Ref. [22], characteristics of pulse, pressure oscillation and frequency were analyzed. The results showed that piston pulser required longer release time to reach pulse peak. However, pyrotechnic pulser had a shorter release time but a steeper pulse peak. Ejecta pulse model for nozzle of motor was put forward in Ref. [25], in which pulse was triggered by transient blockage of nozzle. Pulse amplitude can be expressed as $\delta p / p_{0}=0.71 f J$. A complete description of simplified design guidelines and scaling criteria for pulser design was found in Ref.[26]. It showed that pulse peak was mainly determined by pulse charge and pulse release time. The performances of pulser would be better if pulse release time was twice as the period of combustion chamber in a first-order longitudinal model. For these pulse sources, the predecessors prediction models include ejacta pulse model [25], empirical analysis [12, 21, 25] and shock-tube analysis [20]. The ejacta pulse model is suitable for the cases of nozzle throat area mutation. The empirical analysis is suitable for the cases of additional mass injection. The shock-tube analysis is suitable for the cases of additional high-compressive gas. To study the different velocities of disturbances in solid rocket motors, Smirnov et al developed one-dimensional models of porous compressible propellant [27-29]. In Smirnov's studies, the small disturbances were provided by the combustion of propellant with crack. The small disturbances were periodic and affected by chamber pressure of solid rocket motors.

In previous studies, experimental measurements of pressure-coupling response function, pulse prediction models and one-dimensional models of small disturbances have been reported. However, the characteristics and mechanism of pulse excitation did not been studied in detail. In addition, the previous studies have more attention on the prediction of pulse peak, while ignoring the effects of pulse source on mean pressure. This study aims at understanding characteristics of pulse excitation, which is provided by 
black powder burning in a T-burner. The experimental pressure history of pulse excitation is analyzed. The parameters describing pulse excitation are introduced. The prediction models of pressure pulse and mean pressure increment are established. The geometry of T-burner, the burning properties of BP and are the influence of gas phase parameter considered in models. The influences of burning time and mass flow rate of BP on pressure pulse and mean pressure are studied. The changing laws of pressure pulse and mean pressure are revealed. The influence mechanisms of BP on pulse characteristics are summarized. The results of this study provide a theoretical guidance and a new technical method for the design of pulse excitation in T-burners, and provide the preliminary data for the measurement of pressure-coupling response function of composite propellant, and can be used to explain the phenomena of sudden pressure rise when nonlinear instability combustion is triggered.

\section{Pulse excitation experiment in a T-burner}

In this study, schematic of the T-burner is shown in Fig. 1. A sandwich grain is located on the left end of the T-burner, the sandwich grain is composed of composite propellant and two layers of black powder (BP). One layer of BP is filled between two layers of composite propellants. A normal composite propellant grain is mounted on the right end of the T-burner. According to burning sequence of propellant and BP, the pressure process in T-burner can be divided into five stages. Firstly, two grains are ignited and the burning surface are receded in parallel. The cup shape of grains helps the pressure rising rapidly to equilibrium pressure. Secondly, when the first layer of propellant in the sandwich grain is burned out, the first layer of $\mathrm{BP}$ is ignited. A pressure pulse is triggered in T-burner within a short time. Next, the second layer of propellant is ignited, burning time of the second layer propellant is about $1 \sim 2 \mathrm{~s}$. After the second layer propellant is burned out, the second layer of black powder is ignited, and the pressure pulse is triggered 
again, resulting in a second pulse excitation. Finally, two propellant at both ends are burned out, the pressure in T-burner gradually drops to the atmospheric pressure. While the sandwich grain undergoes these stages, the burning rate of the normal grain at the right end changes with the action of pressure pulse. Due to a large amount of gas released in a short time, compression waves are formed and pressure oscillation is triggered in the T-burner. Difference between the first pulse and second pulse is area of the propellant burning surface. When the first pressure pulse is generated, the area of propellant burning surface is provided by two grains on the both ends of the T-burner. When the second pressure pulse is generated, the area of propellant burning surface is only provided by the normal grain on the right end of the T-burner.

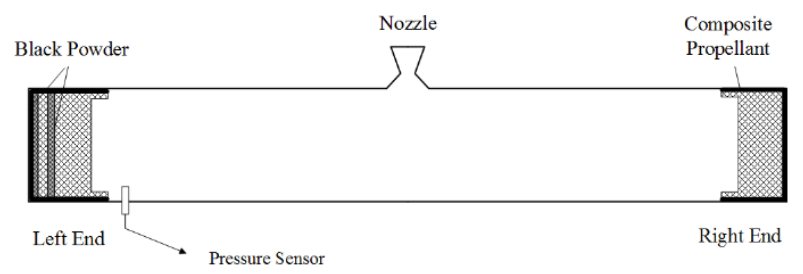

Fig. 1 Schematic of T-burner with two propellant grains.

A pressure sensor is mounted near the propellant burning surface at the left of T-burner, as Fig. 1 shown. Distance from the pressure sensor to the nozzle axis is $1.6 \mathrm{~m}$. Sizes of the T-burner and grain, propellant and BP properties are shown in Table 1. Length of the T-burner is $3.4 \mathrm{~m}$, volume was $0.0216 \mathrm{~m}^{3}$, and area of nozzle throat is $1.81 \times 10^{-5} \mathrm{~m}^{2}$. Burning rate of the propellant can be calculated by the exponential burning rate formula, which is expressed as $r=4.12 p^{0.25} \mathrm{~mm} / \mathrm{s}$ (where, the unit of $p$ is MPa). Density of the propellant is $1800 \mathrm{~kg} / \mathrm{m}^{3}$. When the pressure in T-burner rises to equilibrium pressure, area of the propellant burning surface of one grain is $5.04 \times 10^{-3} \mathrm{~m}^{2}$. The BP employed in the experiments is mixture of large-size black powder (abbreviated as LBP, average particle diameter is about $5 \mathrm{~mm}$ ) and small-size black powder (abbreviated as SBP, average particle diameter is about $1 \mathrm{~mm}$ ). The shapes and sizes of LBP 
and SBP are shown as Fig. 2. Total weight of BP is $50 \mathrm{~g}$. Weight ratio of LBP to SBP is 1:3. Density of BP is $1900 \mathrm{~kg} / \mathrm{m}^{3}[30]$.

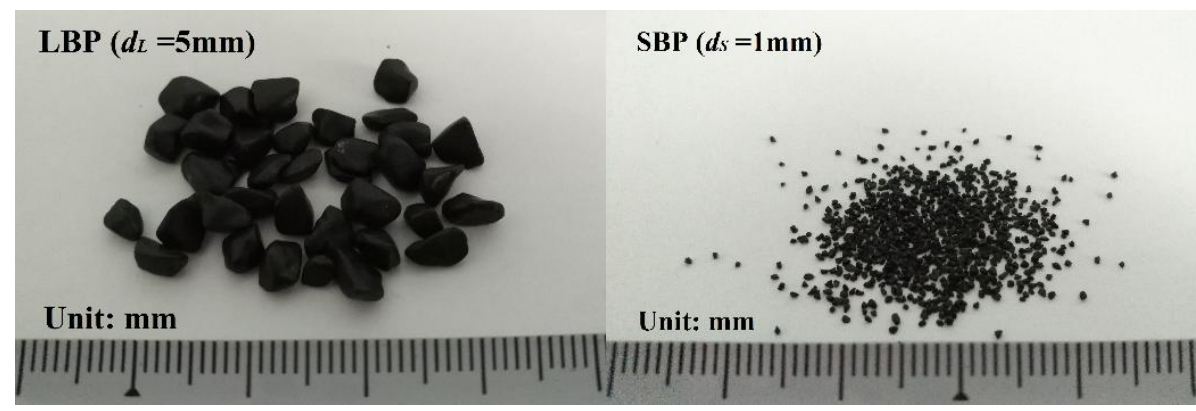

Fig. 2 Shapes and sizes of LBP and SBP

Table 1 Parameters used in T-burner experiments.

\begin{tabular}{cc}
\hline Experimental parameters & Values \\
\hline Length of T-burner $(L)$ & $3.4 \mathrm{~m}$ \\
Volume of T-burner $(V)$ & $0.0216 \mathrm{~m}^{3}$ \\
Area of nozzle throat $\left(A_{t}\right)$ & $1.81 \times 10^{-5} \mathrm{~m}^{2}$ \\
Burning rate of propellant $\left(r_{p}\right)$ & $4.12 p^{0.25} \mathrm{~mm} / \mathrm{s}$ \\
Density of propellant $\left(\rho_{p}\right)$ & $1800 \mathrm{~kg} / \mathrm{m}^{3}$ \\
Area of propellant surface $\left(A_{p}\right)$ & $5.024 \times 10^{-3} \mathrm{~m}^{2}$ \\
Weight of $\operatorname{LBP}\left(\delta m_{b, L}\right)$ & $12.5 \mathrm{~g}$ \\
Weight of SBP $\left(\delta m_{b, S}\right)$ & $37.5 \mathrm{~g}$ \\
Density of BP $\left(\rho_{b}\right)$ & $1900 \mathrm{~kg} / \mathrm{m}^{3}$ \\
Initial particle diameter of LBP $\left(d_{L}\right)$ & $5 \mathrm{~mm}$ \\
Initial particle diameter of SBP $\left(d_{S}\right)$ & $1 \mathrm{~mm}$ \\
\hline
\end{tabular}

A typical $p$ - $t$ curve in a T-burner is shown in Fig. 3 (a), which shows that the pressure rises and oscillates twice when the layers of $\mathrm{BP}$ are ignited. The reason of the pressure rise is that mass flow rate of $\mathrm{BP}$ is much larger than that of propellant. And the pressure oscillation is due to propagation and reflection of the compression waves formed by BP burning. As the figure shows, the pressure histories of two pulses are very similar. Therefore, it is only needed to analyze one of pulses history. The magnification of the first pulse history is shown in Fig. 3 (b). Firstly, the mean pressure increases significantly after BP is ignited. The pressure difference between the maximum of mean pressure and equilibrium pressure is defined as 
mean pressure increment, denoted by $\delta p_{\text {mean }}$. Secondly, there is a significant pressure oscillation. And the first peak of pressure oscillation is defined as pressure pulse, denoted by $\delta p$. The process of forming pressure pulse is called pulse build-up process. The time required for this process is defined as pulse build-up time threshold, denoted by $t_{t h}$. Pulse build-up time threshold is approximately equal to one quarter of the first-order longitudinal period of T-burner. This is due to that the compression waves travel just half length of T-burner during pulse build-up process. Therefore, pulse build-up time threshold can be expressed as Eq. (1).

$$
t_{t h}=0.5 L / a_{c w}=\frac{1}{4} t_{0}
$$

where, $a_{c w}$ is speed of compression wave, which is approximately equal to the local speed of sound and can be calculated by $\sqrt{\gamma_{p} R_{g, p} T_{p}} \cdot t_{0}$ is the first-order longitudinal period of T-burner.
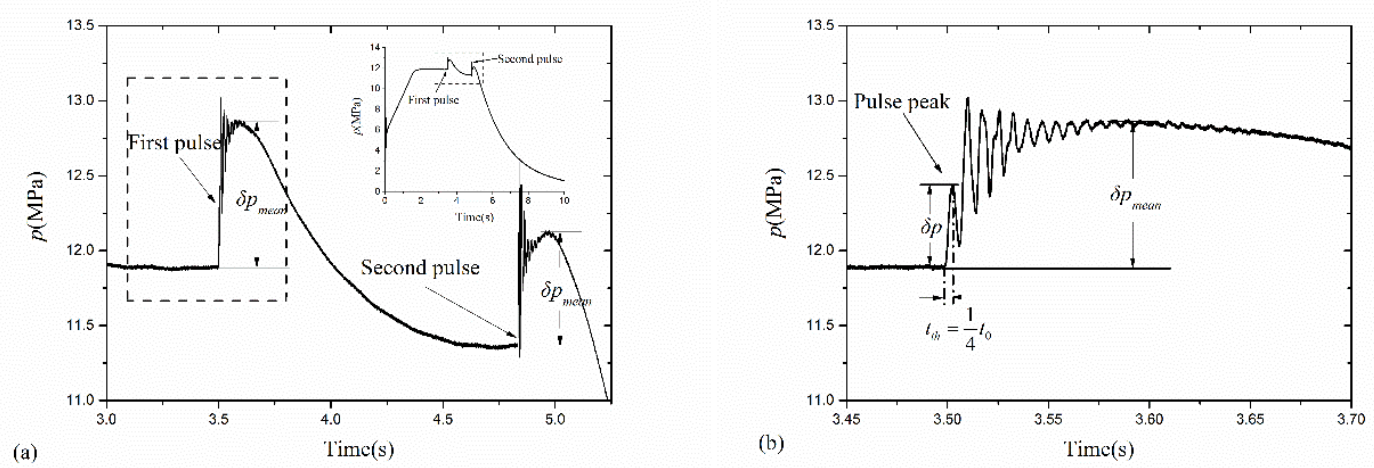

Fig. 3 Typical experimental pressure history with pulse excitation of T-burner: (a) complete curve with two pulses; (b) details of first pulse.

Values of the parameters pointed out in Fig. 3 (b) are shown in Table 2. The equilibrium pressure $\left(p_{0}\right)$ of T-burner is equal to $11.89 \mathrm{MPa}$. Pressure pulse is equal to $0.547 \mathrm{MPa}$, which is $4.6 \%$ of the equilibrium pressure. And mean pressure increment is equal to $0.955 \mathrm{MPa}$, which is $8 \%$ of the equilibrium pressure. The $t_{t h}$ of the $p-t$ curve is equal to $2.23 \mathrm{~ms}$. 
Table 2 Values of pulse parameters.

\begin{tabular}{cc}
\hline Pulse parameters & Values \\
\hline$\delta p_{\text {mean }}$ & $0.955 \mathrm{MPa}$ \\
$\delta p$ & $0.547 \mathrm{MPa}$ \\
$t_{t h}$ & $2.23 \mathrm{~ms}$ \\
\hline
\end{tabular}

From the above analysis, pulse characteristics is reflected in two aspects. One is pressure pulse, as $\delta p$. It determines whether the T-burner experiments can be successful. The other one is mean pressure increment, as $\delta p_{\text {mean }}$. It determines the accuracy of experimental measurement of composite propellant pressure-coupling response function. In addition, $t_{t h}$ is the key parameter to determine pulse build-up time $\left(t_{\text {build }}\right)$.

\section{Theoretical model of T-burner}

The pulse build-up process is shown in Fig. 4. In this process, pressure oscillations begin with traveling waves. When the first layer of BP is ignited, the right end of the T-burner is filled with propellant gas, and the left end of T-burner is filled with BP gas. Pressure at the left end rises rapidly and a compression wave is formed. Similar with the traveling wave, the compression wave moves from left to right. When the wave arrives at the nozzle, some of the high pressure gas flows out through the nozzle, weakening the strength of compression wave. At the same time, pulse build-up process is finished, and the pressure is the peak of pressure pulse. After the compression wave passes the nozzle, it continues to propagate and be reflected in the T-burner. The pressure oscillation is formed and weakened gradually. At the same time, the unburned $\mathrm{BP}$ continues to burn, rising the mean pressure. After the first layer of BP burned out, the mean pressure gradually drops to a new equilibrium pressure. Then, the second layer of BP is ignited, and the above process occurs again. The peak of pressure pulse and mean pressure increment are affected by BP burning properties. In this section, the BP burning, pressure pulse and mean pressure increment are studied theoretically. 


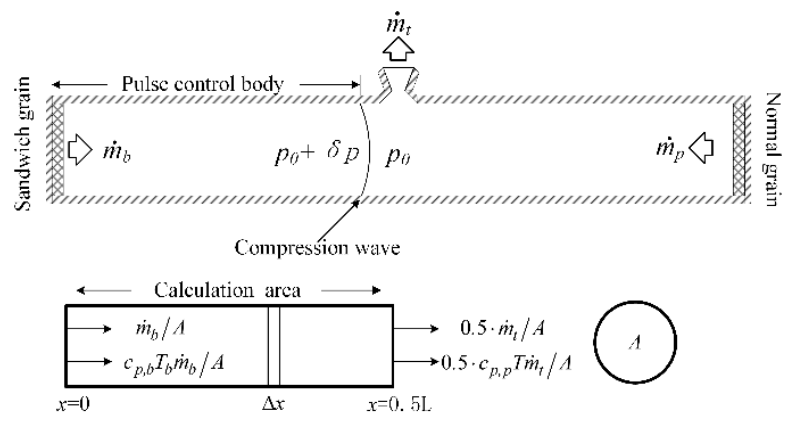

Fig. 4 Schematic of pulse build-up process in a T-burner and the calculation area of models.

Due to the action of compression wave, the pressure of the left part of T-burner rises from $p_{0}$ to $p_{0}+\delta p$. While, the pressure of the remaining part of the T-burner do not change, which is still equal to $p_{0}$. The portion where the pressure rises is defined as the pulse control body, as shown in Fig. 4. The propagation of compression wave from left to right is the expansion process of pulse control body. At the end of process, the volume of pulse control body is the pulse build-up volume, denoted by $V_{b}$. In order to describe pressure change of the pulse control body, zero-dimensional and one-dimensional analysis are employed. According to the previous analysis, pulse control body is located on left side of the T-burner. Therefore, the simplified calculation area is left half of the T-burner, which is shown in Fig. 4. For zero-dimensional analysis, the pressure distribution of pulse control body is ignored. For one-dimensional analysis, the pressure distribution of pulse control body is considered.

\subsection{Burning model of BP}

In the experiments, the mixture of LBP and SBP are used. The burning rate of black powder in a closed chamber can be calculated by Eq. (2) [31]. In experiments, the equilibrium pressure in T-burner is about 12MPa. Then, the burning rate of BP is calculated and equal to $49 \mathrm{~mm} / \mathrm{s}$.

$$
r_{b}=12.2 p^{0.56} \quad 2.5 \mathrm{MPa}<p<25 \mathrm{MPa}
$$

As Fig. 2 shows, BP are irregular particles. In order to simplify the calculation, BP particles are 
assumed as uniform spheres in this model. $\mathrm{D}^{2}$ Law [32] is used to estimate mass flow rate of BP. Assuming all particles of BP are ignited at the same time, the mass flow rate of BP $\left(\dot{m}_{b}\right)$ can be calculated by Eq. (3).

The burning times of $\operatorname{LBP}\left(t_{b, L}\right)$ and $\operatorname{SBP}\left(t_{b, S}\right)$ can be estimated by Eq. (4) and Eq. (5), respectively.

$$
\begin{gathered}
\dot{m}_{b}=\left\{\begin{array}{cc}
6 \delta m_{b, L}\left(d_{L}-2 r_{b} t\right)^{2} r_{b} / d_{L}^{3}+6 \delta m_{b, S}\left(d_{S}-2 r_{b} t\right)^{2} r_{b} / d_{S}^{3} & 0<t<t_{b, S} \\
6 \delta m_{b, L}\left(d_{L}-2 r_{b} t\right)^{2} r_{b} / d_{L}^{3} & t_{b, S}<t<t_{b, L}
\end{array}\right. \\
t_{b, L}=d_{L} / 2 r_{b} \\
t_{b, S}=d_{S} / 2 r_{b}
\end{gathered}
$$

where, $d_{L}$ and $d_{S}$ are the initial diameters of LBP and SBP. For single diameter BP, the mass flow rate can be calculated by Eq. (3)-2, and the burning time can be estimated by Eq. (4) and Eq. (5).

\subsection{Prediction model of pressure pulse}

In this section, zero-dimensional and one-dimensional models are built to predict the pressure pulse.

Here, the zero-dimensional model is introduced firstly. For zero-dimensional model, quasi-steady assumption is employed to simplify the equations. As shown in Fig. 4, when BP is ignited, the intake of left end is provided by BP burning, and the intake of right end is provided by propellant burning. The gas exits the T-burner through the nozzle. Therefore, the mass equation of T-burner can be written as:

$$
d m / d t=\dot{m}_{b}+\dot{m}_{p}-\dot{m}_{t}
$$

where, $\dot{m}_{b}$ is mass flow rate of BP, which can be calculated by Eq. (3). $\dot{m}_{p}$ is mass flow rate of propellant of one grain, which can be calculated by $\dot{m}_{p}=A_{p} \cdot \rho_{p} \cdot a p^{n} . A_{p}$ is area of propellant burning surface of one grain. $\dot{m}_{t}$ is outlet mass flow rate of nozzle, which can be written as $\dot{m}_{t}=\Gamma p_{0} A_{t} / \sqrt{R_{g, p} T_{p}}$. $A_{t}$ is area of nozzle throat, and constant $\Gamma$ can be calculated by $\Gamma=\left(\frac{2}{\gamma_{p}+1}\right)^{\frac{\gamma_{p+1}}{2\left(\gamma_{p}-1\right)}} \sqrt{\gamma_{p}}$. The total weight 
of gas in the T-burner can be expressed as Eq. (7).

$$
m=\rho_{g} V
$$

where, $V$ is volume of T-burner, which can be expressed as Eq. (8).

$$
V=A \cdot L
$$

where, $A$ is cross-sectional area of T-burner.

When the heat dissipation of T-burner is ignored, the energy change in T-burner is mainly determined by the heat carried by BP gas, the heat carried by propellant gas, and the heat carried by exhaust gas of nozzle. The process of energy change in T-burner is isovolumic. The processes of propellant burning and nozzle exhaust are isobaric. When BP is ignited, the local pressure rises and inflates immediately. Therefore, the process of BP burning is closer to isobaric state. $\bar{T}$ is the mean temperature of T-burner, which is used to describe the energy change of T-burner. Since the T-burner has been filled with propellant gas prior to pulse triggering and pulse build-up time threshold is very short (about $1.6 \mathrm{~ms}$ ), the BP gas has little effect on the propellant of right end or the nozzle. Therefore, the gas parameters in propellant term and nozzle term should be the gas parameters of propellant gas. The gas parameters in energy change term should be equal to the gas parameters of local mixture. However, without the detailed compositions, the gas parameters of local mixture can't be solved. The left end of T-burner is the main region of energy changing and filled with BP gas. Therefore, the gas parameters of local mixture are replaced by the gas parameters of BP gas. Based on the above analysis, the energy equation of T-burner can be expressed as:

$$
d\left(c_{v, b} \bar{T} m\right) / d t=c_{p, b} T_{b} \dot{m}_{b}+c_{p, p} T_{p} \dot{m}_{p}-c_{p, p} \bar{T} \dot{m}_{t}
$$

where, $T_{b}$ is temperature of BP gas. $T_{p}$ is temperature of propellant gas. $c_{v, b}$ and $c_{p, b}$ are constant pressure and constant volume heat capacity of BP gas, respectively. $c_{p, p}$ is constant pressure heat 
capacity of propellant gas. All kinds of gases are assumed to be ideal gas. Ideal gas equation of T-burner is used to supplement Eq. (6) and Eq. (9). In the state equation, the gas is considered as a mixture gas. During the process of pulse build-up, the majority of gas in T-burner is propellant gas. The impact of BP gas is small and can be ignore. The parameters of mixture gas are replaced by those of propellant burning gas.

Therefore, the state equation can be written as Eq. (10).

$$
p=\rho_{g} R_{g, p} \bar{T}
$$

By substituting Eq. (10) into Eq. (7), the total weight of gas in T-burner can be rewritten as:

$$
m=p V / R_{g, p} \bar{T}
$$

By substituting Eq. (11) into Eq. (9), Eq. (9) is transformed to:

$$
d\left(c_{v, b} \cdot \bar{T} \frac{p V}{R_{g, p} \cdot \bar{T}}\right) / d t=c_{p, b} T_{b} \dot{m}_{b}+c_{p, p} T_{p} \dot{m}_{p}-c_{p, p} \bar{T} \dot{m}_{t}
$$

In the left term of Eq. (12), $\bar{T}$ is on both the numerator and the denominator, so $\bar{T}$ is eliminated. $R_{g, p}$ is the gas constant of propellant gas, which is a constant. $c_{v, b}$ is a function of temperature. Compared with the change of pressure, the change of temperature is very small within pulse build-up process. Therefore, $c_{v, b}$ is consider as a constant. $V$ is the volume of T-burner. The initial volume of T-burner is $2.16 \times 10^{-2} \mathrm{~m}^{3}$. The volume changed by BP and propellant burning is $2.96 \times 10^{-4} \mathrm{~m}^{3}$ at most, which is much smaller the initial volume of T-burner. Therefore, the volume change is ignored, and $V$ is considered as a constant. In this case, $p$ is the only variable in the left item of Eq. (12). Eq. (12) be transformed into:

$$
d p / d t=R_{g, p} \cdot\left(\frac{c_{p, b}}{c_{v, b}} T_{b} \dot{m}_{b}+\frac{c_{p, p}}{c_{v, b}} T_{p} \dot{m}_{p}-\frac{c_{p, p}}{c_{v, b}} \bar{T}_{t}\right) / V
$$

Let $\alpha=c_{v, p} / c_{v, b}$ and $\gamma=c_{p} / c_{v}$, a differential equation with pressure as a variable can be derived, 
shown as Eq. (14).

$$
d p / d t=R_{g, p} \cdot\left(\gamma_{b} T_{b} \dot{m}_{b}+\gamma_{p} T_{p} \dot{m}_{p}-\alpha \cdot \gamma_{p} \bar{T} \dot{m}_{t}\right) / V
$$

Note that only the right third term of Eq. (14) contains the variable $\bar{T}$. It is the nozzle term. It can be seen from the previous analysis that the state of nozzle is same as the state before BP is ignited. Therefore, the $\bar{T}$ in the right third term of Eq. (14) can be replaced by $T_{p}$. In this case, the growth rate of pressure can be written as Eq. (15).

$$
d p / d t=R_{g, p} \cdot\left(\gamma_{b} T_{b} \dot{m}_{b}+\alpha \cdot \gamma_{p} T_{p} \dot{m}_{p}-\alpha \cdot \gamma_{p} T_{p} \dot{m}_{t}\right) / V \quad t<t_{b}
$$

where, $t_{b}$ is burning time of $\mathrm{BP}$.

Eq. (15) is derived with the zero-dimensional assumption, which describes the slope of mean pressure rise of the whole T-burner. But the fact is that, under action of the compression wave, only the pressure in pulse control body rises, and the pressure in other place remains constant. Therefore, Eq. (15) needs to be revised. In order to figure this out, a new variable is defined as the ratio between the volume of pulse control body to the volume of T-burner, named volume coefficient, denoted by $\beta$. Its definition is:

$$
\beta=V / V_{b}
$$

where, $V_{b}$ is volume of pulse control body, which can be written as:

$$
V_{b}=A \cdot a_{c w} \cdot t_{b u i l d}
$$

where, $t_{\text {build }}$ is pulse build-up time. Through volume coefficient $(\beta)$, the zero-dimensional differential equation is modified to a quasi-one-dimensional differential equation. As the same reason, the mass flow rate of nozzle and propellant of the right end are unchanged, as $2 \dot{m}_{p}=\dot{m}_{t}$. In addition, before BP is ignited, the pressure of T-burner is equal to $p_{0}$. Then, $\dot{m}_{p}$ is equal to $A_{p} \cdot \rho_{p} \cdot a p_{0}^{n}$. Therefore, Eq. (15) can be 
rewritten as Eq. (18), the modified zero-dimensional differential equation of pressure, which is growth rate of the pressure in pulse control body.

$$
d p / d t=\beta R_{g, p} \cdot\left(\gamma_{b} T_{b} \dot{m}_{b}-\alpha \cdot \gamma_{p} T_{p} \dot{m}_{p}\right) / V
$$

Except growth rate of the pressure in the pulse control body, the other factor affecting the pressure pulse is pulse build-up time $\left(t_{\text {build }}\right)$. The pulse build-up time is determined by pulse build-up time threshold $\left(t_{t h}\right)$ and burning time of $\mathrm{BP}\left(t_{b}\right)$. If burning time of BP is less than time threshold $\left(t_{b}<t_{t h}\right)$, BP is burned out within $t_{t h}$. All the burned gas of BP can be used to generate the pressure pulse. The pressure build-up time can be taken as $t_{b u i l d}=t_{b}$. If burning time of BP is larger than time threshold $\left(t_{b}>t_{t h}\right)$, only the BP burned within $t_{t h}$ can be used to generate the pressure pulse. And the rest BP is used to increase mean pressure of T-burner. Pressure build-up time can be taken as $t_{\text {build }}=t_{t h}$. According to the value of $t_{b}$ and $t_{t h}$, the peak of pressure pulse ( $\left.\delta p\right)$ can be written as Eq. (19).

$$
\begin{cases}\delta p=\int_{0}^{t_{\text {build }}} d p / d t=\beta R_{g, p} \cdot\left(\gamma_{b} T_{b} \delta m_{b}-\alpha \cdot \gamma_{p} T_{p} \dot{m}_{p} t_{b}\right) / V & t_{b}<t_{t h} \\ \delta p=\int_{0}^{t_{\text {bulild }}} d p / d t=\beta R_{g, p} \cdot\left(\gamma_{b} T_{b} \int_{0}^{t_{h}} \dot{m}_{b} d t-\alpha \cdot \gamma_{p} T_{p} \dot{m}_{p} t_{t h}\right) / V & t_{b}>t_{t h}\end{cases}
$$

where, $\delta m_{b}$ is BP weight.

The effective weight of BP is introduced to describe the relationship between the weight of BP burned within pulse build-up time threshold, denoted by $m_{b, e}$. The effective weight fraction is introduced to describe the relationship between the effective weight and weight of BP, denoted by $\eta$. The definitions of $m_{b, e}$ and $\eta$ can be expressed as Eq. (20) and Eq. (21), respectively.

$$
\begin{aligned}
& \begin{cases}m_{b, e}=\delta m_{b} & t_{b}<t_{t h} \\
m_{b, e}=\int_{0}^{t_{b h}} \dot{m}_{b} d t & t_{b}>t_{t h}\end{cases} \\
& \eta=m_{e} / \delta m_{p}= \begin{cases}1 & t_{b}<t_{t h} \\
\int_{0}^{t_{t h}} \dot{m}_{b} d t / \delta m_{p} & t_{b}>t_{t h}\end{cases}
\end{aligned}
$$


By substituting Eq. (20) and Eq. (21)into Eq. (19), the pressure pulse $\delta p$ can be rewritten as:

$$
\delta p=\beta R_{g, p} \cdot\left(\eta \cdot \gamma_{b} T_{b} \delta m_{b}-\alpha \cdot \gamma_{p} T_{p} \dot{m}_{p} t_{\text {build }}\right) / V
$$

In addition, according to Eq. (8), Eq. (16) and Eq. (17), volume coefficient $\beta$ can be rewritten as:

$$
\begin{cases}\beta=2 L /\left(a_{c w} \cdot t_{b}\right) & t_{b}<t_{t h} \\ \beta=2 & t_{b}>t_{t h}\end{cases}
$$

By Eq. (22), with the parameters of BP and propellant, the pressure pulse in T-burner can be predicted. So far, modified zero-dimensional model of pressure pulse is completed. Next, one-dimensional model of pressure pulse is introduced.

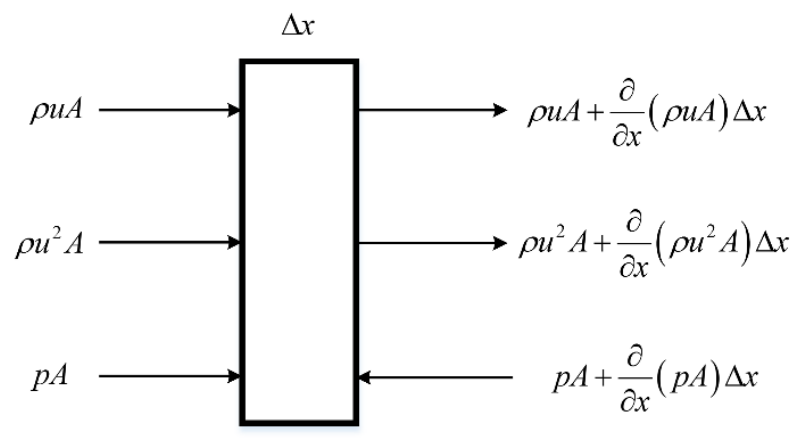

Fig. 5 Micro-element body of one-dimensional model.

The micro-element body of one-dimensional model is shown as Fig. 5. When heat loss and heat conduction are ignored, the mass, momentum and energy of entry and exit of micro-element body can be expressed as Fig. 5. Within the time interval $\Delta t$, the mass change of micro-element body is equal to the mass outflowing the micro-element body minus the mass inflowing the micro-element body. Momentum change and energy change of micro-element body are obtained in the same way. After finishing the equations, the one-dimensional unsteady equations of mass, momentum and energy are shown as Eq. (24). 


$$
\left\{\begin{array}{l}
\frac{\partial \rho}{\partial t}+\frac{\partial \rho u}{\partial x}=0 \\
\frac{\partial \rho u}{\partial t}+\frac{\partial\left(\rho u^{2}+p\right)}{\partial x}=0 \\
\frac{\partial \rho\left(\frac{u^{2}}{2}+e\right)}{\partial t}+\frac{\partial\left[\rho u\left(\frac{u^{2}}{2}+e\right)+p u\right]}{\partial x}=0 \\
p=(k-1) \rho e
\end{array}\right.
$$

The ideal gas equation of state is used to enclose the equations. $e$ is internal energy, which can be expressed as $e=c_{v, p} T$. The calculation area is shown as Fig. 4. The left boundary conditions are controlled by burning of BP. Mass flux ( $\left.\phi_{m}\right)$ and energy flux $\left(\phi_{e}\right)$ of left boundary can be expressed as:

$$
\left\{\begin{array}{l}
\left.\phi_{m}\right|_{x=0}=\dot{m}_{b} / A \\
\left.\phi_{e}\right|_{x=0}=c_{p, b} T_{b} \dot{m}_{b} / A
\end{array}\right.
$$

The right boundary conditions are controlled by flow of nozzle. Mass flux and energy flux of right boundary can be expressed as:

$$
\left\{\begin{array}{l}
\left.\phi_{m}\right|_{x=0.5 L}=0.5 \cdot \dot{m}_{t} / A \\
\left.\phi_{e}\right|_{x=0.5 L}=0.5 \cdot c_{p, p} T \dot{m}_{t} / A
\end{array}\right.
$$

Two-step method of the Lax-Wendroff scheme is employed to solve the equations. Then, Eq. (24) is transformed into Eq. (27).

$$
\frac{\partial \boldsymbol{u}}{\partial t}+\frac{\partial \boldsymbol{f}(\boldsymbol{u})}{\partial x}=\boldsymbol{0}
$$

where, $\boldsymbol{f}(\boldsymbol{u})$ is a function of $\boldsymbol{u} . \boldsymbol{u}$ and $\boldsymbol{f}(\boldsymbol{u})$ can be expressed as Eq. (28) and Eq. (29), respectively.

$$
\boldsymbol{u}=\left[\begin{array}{l}
\rho \\
\rho u \\
\rho u^{2} / 2+p /(k-1)
\end{array}\right]=\left[\begin{array}{l}
\rho \\
m \\
E
\end{array}\right]
$$




$$
\boldsymbol{f}(\boldsymbol{u})=\left[\begin{array}{l}
0 \\
p \\
p u
\end{array}\right]+u \boldsymbol{u}=\left[\begin{array}{l}
m \\
\frac{m}{\rho^{2}}+(k-1)\left(E-\frac{m^{2}}{2 \rho}\right) \\
\left(E+(k-1)\left(E-\frac{m^{2}}{2 \rho}\right)\right) \frac{m}{\rho}
\end{array}\right]
$$

The initial conditions of Eq. (24) is shown as Eq. (30).

$$
\left\{\begin{array}{l}
\left.\phi_{m}\right|_{t=0}=0.5 \cdot \dot{m}_{t} / A \\
\left.\phi_{e}\right|_{t=0}=0.5 \cdot c_{p, p} T_{p} \dot{m}_{t} / A \\
\left.p\right|_{t=0}=p_{0}
\end{array}\right.
$$

So far, the one-dimensional model of pressure pulse is completed. Based on MATLAB, the one-dimensional model can be solved. The pressure distributions at different times are shown in Fig. 6 . During the pulse build-up process, pressure pulse spreads from left to right with time. According to definition of the pulse control body, volume of the pulse control body increases time. As Fig. 6 shows, pressure distribution can be divided into two parts. The first part is low pressure zone, whose pressure is equal to equilibrium pressure $\left(p_{0}\right)$. The second part is high pressure zone, defined as the pulse control body. At the front of pulse control body, there is a thin compression layer, which is decaying rapidly with time. Therefore, the compression layer has little impact on pressure pulse. Except the compression layer, pressure distribution of pulse control body is uniform, which is equal to 0.774MPa. With the same boundary conditions and initial conditions, the pressure pulse predicted by modified zero-dimensional model is equal to $0.77 \mathrm{MPa}$, which is very close to the result of one-dimensional model. This indicates that the modified zero-dimensional model can accurately predict the pressure pulse. In addition, the one-dimensional model only can be solved numerically and it takes a long time. Therefore, in following discussions, the modified zero-dimensional model is discussed in detail. Due to the limitations of assumptions in models, the model of pressure pulse can only be used to predict the pressure pulse of BP 
burning.

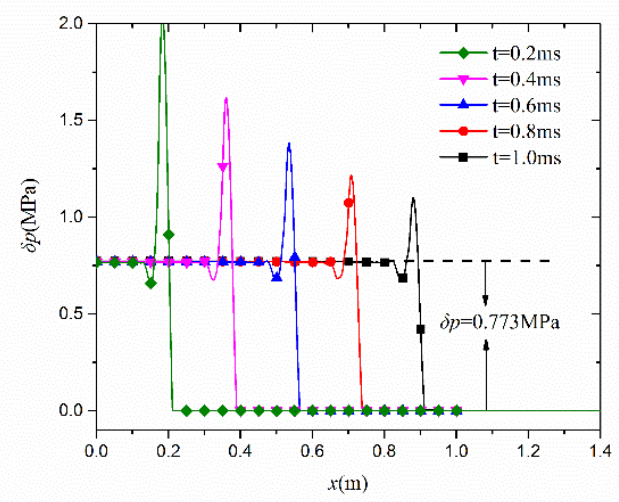

Fig. 6 One-dimensional distribution of pressure changed with time.

\subsection{Prediction model of mean pressure}

Pressure oscillation can be divided into two parts. One part is pressure fluctuation, which is studied in Section 3.2. The other part is mean pressure. Starting from the pulse triggered, it needs a long time for T-burner to reach the maximum mean pressure. The formed time of maximum mean pressure is about 50 100 times the pulse build-up time. Therefore, pressure and temperature of T-burner can be consider as uniform. Therefore, zero-dimensional model in this section is used to solve the change of mean pressure within T-burner. As the mass flow rate of BP is much larger than that of propellant, a lot of gas is injected into the T-burner in a short time, rising the mean pressure of T-burner. This process can also be described by the mass equation and the energy equation of T-burner, shown as Eq. (6) and Eq. (9), respectively. Unlike the analysis of pressure pulse, the burning time of BP is long enough that BP gas can affect the entire T-burner. In this process, the burning rate of propellant and the nozzle state changes with mean pressure. In addition, the change of mean temperature can't be ignored anymore. With the state equation of ideal gas, the energy equation of T-burner Eq. (9) has been rewritten as Eq. (14), which is a differential 
equation with pressure as a variable. By substituting Eq. (11) and Eq. (14) into Eq. (6), a differential equation with mean temperature as a variable can be derived, shown as Eq. (31).

$$
\frac{1}{\bar{T}} \cdot d \bar{T} / d t=R_{g, p} \cdot\left[\left(\gamma_{b} T_{b} / \bar{T}-1\right) \bar{T} \dot{m}_{b}+\left(\alpha \cdot \gamma_{p} T_{p} / \bar{T}-1\right) \bar{T} \dot{m}_{p}-\left(\alpha \cdot \gamma_{p}-\right) R \bar{T} \dot{m}_{t}\right] / p V
$$

Combine Eq. (14) and Eq. (31) into a set of differential equations, shown as Eq. (32). Using Eq. (32), the mean pressure history of T-burner after BP ignited can be solved.

$$
\left\{\begin{array}{l}
d p / d t=R_{g, p} \cdot\left(\gamma_{b} T_{b} \dot{m}_{b}+\alpha \cdot \gamma_{p} T_{p} \dot{m}_{p}-\alpha \cdot \gamma_{p} \bar{T} \dot{m}_{t}\right) / V \\
\frac{1}{\bar{T}} \cdot d \bar{T} / d t=R_{g, p} \cdot\left[\left(\gamma_{b} T_{b} / \bar{T}-1\right) \bar{T} \dot{m}_{b}+\left(\alpha \cdot \gamma_{p} T_{p} / \bar{T}-1\right) \bar{T} \dot{m}_{p}-\left(\alpha \cdot \gamma_{p}-1\right) R \bar{T} \dot{m}_{t}\right] / p V
\end{array}\right.
$$

Since the Eq. (32) are partial differential equations, the Runge-Kutta method (MATLAB, ode45) is employed to solve the equations. The initial conditions for Eq. (32) solving can be expressed as:

$$
\left\{\begin{array}{l}
p=p_{0} \\
\bar{T}=T_{p}
\end{array}, t=0\right.
$$

\subsection{Calculation of gas parameters}

In this study, the gas parameters include gas constant, constant pressure heat capacity, constant volume heat capacity and specific heat ratio. Due to differences in the component of BP gas and propellant gas, the gas parameters of each fuel needs to calculate, respectively. The gas constant of mixture $\left(R_{g}\right)$ is equal to the ideal gas constant $(R)$ divided by the average molar mass of mixture $(\bar{M})$, which can be expressed as Eq. (34). And the average molar mass of mixture can be calculated by Eq. (35).

$$
\begin{gathered}
R_{g}=R / \bar{M} \\
\bar{M}=\frac{1}{n(\text { total })} \sum_{i} n(i) \cdot M(i)
\end{gathered}
$$

where, $n(i)$ is the molar amount of component $i, M(i)$ the molar mass of component $i, n($ total $)$ is the total molar amount of the mixed gas. Constant pressure heat capacity of each component is a function of 
temperature, which can be expressed as Eq. (36). The polynomial coefficients of $c_{p}(i)$ are taken from therom.inp of NASA CEA.

$$
c_{p}(i) / R_{g}(i)=a_{1} T^{-2}+a_{2} T^{-1}+a_{3}+a_{4} T+a_{5} T^{2}+a_{6} T^{3}+a_{7} T^{4}
$$

Constant volume heat capacity of each component can be calculated by Meyer Formula, which is shown as Eq. (37).

$$
c_{p}(i)=c_{v}(i)+R_{g}(i)
$$

The constant pressure heat capacity and constant volume heat capacity of the mixture can be expressed as Eq. (38) and Eq. (39)[33], respectively.

$$
\begin{aligned}
& c_{p}=\frac{1}{n(\text { total })} \sum_{i} n(i) \cdot c_{p}(i) \\
& c_{v}=\frac{1}{n(\text { total })} \sum_{i} n(i) \cdot c_{v}(i)
\end{aligned}
$$

The components and temperature of BP gas are shown in Table 3, which are calculated by the ideal equivalent principal reaction equation of $\mathrm{BP}$ [34], shown as Eq. (40). When the mass faction of $\mathrm{KNO}_{3}$ is about $75 \%$, the heat of $\mathrm{BP}(\Delta Q)$ is equal to $3080 \mathrm{~kJ} / \mathrm{kg}$ [30]. The calculated temperature of BP is $2154 \mathrm{~K}$. In $\mathrm{BP}$ gas, the components of top three mole fractions are $\mathrm{CO}, \mathrm{CO}_{2}$ and $\mathrm{N}_{2}$ by turns. In addition, the products of BP burning contain condensed phase. And mass fraction of the condensed phase $\left(\mathrm{Y}_{\mathrm{P}}\right)$ is about 0.46

$$
\begin{aligned}
& 32 \mathrm{KNO}_{3}+4 \mathrm{C}_{12} \mathrm{H}_{4} \mathrm{O}_{2}+10 \mathrm{~S} \rightarrow 9 \mathrm{~K}_{2} \mathrm{CO}_{3}+4 \mathrm{~K}_{2} \mathrm{SO}_{4} \\
& +3 \mathrm{~K}_{2} \mathrm{~S}+28 \mathrm{CO}+2 \mathrm{SO}_{2}+\mathrm{H}_{2} \mathrm{~S}+11 \mathrm{CO}_{2}+16 \mathrm{~N}_{2}+7 \mathrm{H}_{2} \mathrm{O} \quad \Delta Q=3080 \mathrm{~kJ} / \mathrm{kg}
\end{aligned}
$$

Table 3 Components and temperature of BP gas.

\begin{tabular}{cc}
\hline Components & Mole fractions \\
\hline $\mathrm{CO}$ & 0.391 \\
$\mathrm{CO}_{2}$ & 0.241 \\
$\mathrm{~N}_{2}$ & 0.223
\end{tabular}




\begin{tabular}{cc}
$\mathrm{SO}_{2}$ & 0.064 \\
$\mathrm{H}_{2} \mathrm{O}$ & 0.063 \\
$\mathrm{H}_{2} \mathrm{~S}$ & 0.017 \\
$\mathrm{Yp}$ & 0.46 \\
$T_{b}(\mathrm{~K})$ & 2154 \\
\hline
\end{tabular}

The components and temperature of propellant gas are shown in Table 4, which are calculated by NASA CEA. The temperature of propellant gas is about $2693 \mathrm{~K}$. In propellant gas, the components of top three mole fractions are $\mathrm{H}_{2}, \mathrm{CO}$ and $\mathrm{H}_{2} \mathrm{O}$ by turns. The heat capacity of $\mathrm{H}_{2}$ and $\mathrm{H}_{2} \mathrm{O}$ are much larger than other components. So the heat capacity of propellant gas is larger than that of BP gas.

Table 4 Components and temperature of propellant gas.

\begin{tabular}{cc}
\hline Components & Mole fractions \\
\hline $\mathrm{H}_{2}$ & 0.32005 \\
$\mathrm{CO}$ & 0.26364 \\
$\mathrm{H}_{2} \mathrm{O}$ & 0.14532 \\
$\mathrm{HCL}$ & 0.13092 \\
$\mathrm{~N}_{2}$ & 0.06812 \\
$\mathrm{AL}_{2} \mathrm{O}_{3}(\mathrm{~L})$ & 0.03664 \\
$\mathrm{CO}_{2}$ & 0.01785 \\
$T_{p}(\mathrm{~K})$ & 2693 \\
\hline
\end{tabular}

According to Eq. (22) and Eq. (32), the gas parameters needed to be calculated include the gas constant of propellant gas $\left(R_{g, p}\right)$, the specific heat ratio of propellant gas $\left(\gamma_{p}\right)$, the specific heat ratio of BP gas $\left(\gamma_{b}\right)$ and the ratio between constant volume heat capacity of BP gas to that of propellant gas $(\alpha)$. By substituting the data in Table 3and Table 4 into Eq.(34) (39), the four parameters can be calculated. The results are shown in Table 5. The gas constant of propellant gas is equal to $361.4 \mathrm{~J} /(\mathrm{kg} \cdot \mathrm{K})$. When the temperature of propellant gas is $2693 \mathrm{~K}$, the specific heat ratio of propellant gas is equal to 1.159 . When temperature of BP gas is $2154 \mathrm{~K}$, the specific heat ratio of BP gas is equal to 1.255 . And $\alpha$ is equal to 1.897 . 
Table 5 Gas phase parameters of BP and propellant gas.

\begin{tabular}{cc}
\hline Parameters & Values \\
\hline$R_{g, p} \mathrm{~J} /(\mathrm{kg} \cdot \mathrm{K})$ & 361.4 \\
$\gamma_{p}(2693 \mathrm{~K})$ & 1.159 \\
$\gamma_{b}(2154 \mathrm{~K})$ & 1.255 \\
$\alpha$ & 1.897 \\
\hline
\end{tabular}

\section{Experimental verification}

To verify accuracy of the theoretical models, combustion tests in T-burner are conducted. The experimental setup and methods are the same as that in Ref. [5] and Ref. [35]. The experimental parameters are shown in Table 1. The pressure sensor is mounted as shown in Fig. 3 (a). The distance from the pressure sensor to the nozzle axis is $1.6 \mathrm{~m}$. In this section, the theoretical analysis of pressure pulse and mean pressure are verified by experiments, respectively.

\subsection{Verification of pressure pulse}

In order to eliminate influence of the randomness of BP burning, three repetitive experiments are carried out in this study. And contains two pulses are generated in each experiment. Six pulses have the same composition of BP, as shown in Table 1. According to the data in Table 1, the parameters given in Eq. (22) can be calculated. The results are shown in Table 6 . The burning time of BP $\left(t_{b}\right)$ is determined by the burning time of $\operatorname{LBP}\left(t_{b, L}\right)$, which can be calculated by Eq.(4). When the initial particle of LBP is $5 \mathrm{~mm}$, the burning time of BP is equal to $51 \mathrm{~ms}$. The theoretical $t_{t h}$ can be calculated by Eq. (1), where $a_{c w}$ is equal to $1055 \mathrm{~m} / \mathrm{s}$, calculated by $\sqrt{\gamma_{p} R_{g, p} T_{p}}$. Thus $t_{t h}$ is equal to $1.61 \mathrm{~ms}$. According to the theoretical analysis of pressure pulse, when $t_{b}$ is bigger than $t_{t h}, t_{\text {build }}$ is equal to $t_{t h}$, and $\beta$ is equal to 2 . The weight of BP is equal to the sum weight of LBP and SBP, which is $50 \mathrm{~g}$. In the products of BP burning, there are a lot of condensed phase components. According to the data in Table 3, the mass fraction of BP 
condensed phase components is 0.46 . This part of BP burning products has little effect on gas phase. It must be removed from the BP weight. According to Eq.(3) and Eq. (21), the $\eta$ can be calculated, which is equal to 0.325 . And $\dot{m}_{p}$ can be calculated by $A_{p} \cdot \rho_{p} \cdot a p_{0}^{n}$, which is equal to $0.069 \mathrm{~kg} / \mathrm{s}$. By substituting the parameters in Table 5 and Table 6 into Eq. (22), pressure pulse can be calculated, which is equal to 0.77 MPa.

Table 6 The values of parameters given in Eq. (22).

\begin{tabular}{cc}
\hline Parameters & Values \\
\hline$t_{\text {build }}(\mathrm{ms})$ & 1.61 \\
$\beta$ & 2 \\
$\delta m_{b}(\mathrm{~g})$ & $\left(1-\mathrm{Y}_{\mathrm{p}}\right) * 50$ \\
$\eta$ & 0.325 \\
$\dot{m}_{p}(\mathrm{~kg} / \mathrm{s})$ & 0.069 \\
\hline
\end{tabular}

The experimental pressure history of six pulses are shown as Fig. 7 (a) (f). Fig. 7 (a) and Fig. 7 (b) are the first pulse and second pulse of test 1, respectively. Fig. 7 (c) and Fig. 7 (d) are the first pulse and second pulse of test 2, respectively. Fig. 7 (e) and Fig. 7 (f) are the first pulse and second pulse of test 3, respectively. In each figure, solid line represents the experimental pressure oscillation, and dotted line represents the theoretical pressure pulse. The pressure oscillation of each pulse is triggered successfully. Each pressure pulse is pointed out on each figure. The six pressure pulses of three tests are equal to 0.547 $\mathrm{MPa}, 0.736 \mathrm{MPa}, 0.786 \mathrm{MPa}, 0.74 \mathrm{MPa}, 0.636 \mathrm{MPa}$ and $0.799 \mathrm{MPa}$ in turns. Each pressure pulse is different from others, which is caused by the randomness of BP burning.

All figures of Fig. 7 show a good agreement between theoretical and experimental pressure pulse. Comparisons and errors of six experimental and theoretical pressure pulses are shown in Table 7. Compared with one value of theoretical pressure pulse, the experimental pressure pulse is distributed in a range of $0.55 \sim 0.8 \mathrm{MPa}$. This indicates that the randomness of BP burning is unavoidable. Except the first 
pulse of test 1 and the first pulse of test 3 , the errors of other pulses are less than $\pm 5 \%$. It indicates that the theoretical analysis of pressure pulse is reasonable. And the accuracy of Eq. (22) is about 95\%
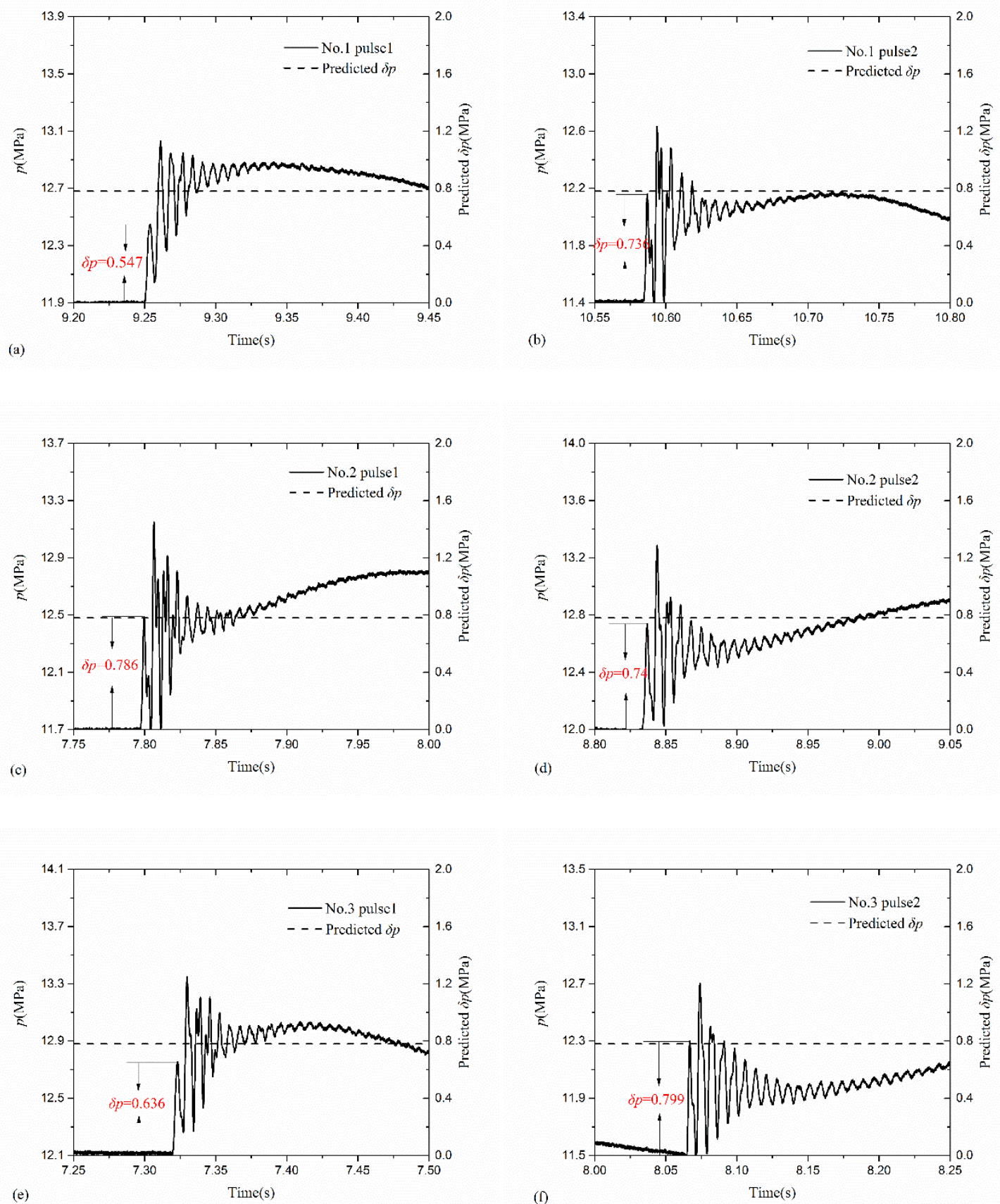

Fig. 7 Six pressure pulse of three T-burner tests.

Table 7 Comparisons of experimental and theoretical pressure pulse.

\begin{tabular}{cccccc}
\hline & Test No. & Theoretical $\delta p / \mathrm{MPa}$ & Measured $\delta p / \mathrm{MPa}$ & Errors & Figure No. \\
\hline \multirow{2}{*}{1} & $1^{\text {st }}$ Pulse & \multirow{2}{*}{0.77} & 0.547 & $-28.9 \%$ & Fig. 7 (a) \\
& $2^{\text {nd }}$ Pulse & & 0.736 & $-4.4 \%$ & Fig. 7 (b)
\end{tabular}




\begin{tabular}{cccccc}
2 & $1^{\text {st }}$ Pulse & 0.77 & 0.786 & $2.1 \%$ & Fig. 7 (c) \\
& $2^{\text {nd }}$ Pulse & & 0.74 & $-3.9 \%$ & Fig. 7 (d) \\
3 & $1^{\text {st }}$ Pulse & \multirow{2}{*}{0.77} & 0.636 & $-17.4 \%$ & Fig. 7 (e) \\
& $2^{\text {nd }}$ Pulse & & 0.799 & $3.8 \%$ & Fig. 7 (f) \\
\hline
\end{tabular}

\subsection{Verification of mean pressure}

In this part, the theoretical analysis of mean pressure is validated by comparing the theoretical mean pressure history and experimental mean pressure history. The experimental mean pressure history is obtained by the experimental pressure history minus the pressure oscillation, which eliminates the impact of pressure oscillation. As the pulse process is very similar with the ignition process of solid rocket, the ignition pressure empirical formula [36] is also employed to calculate the mean pressure increment $\left(\delta p_{\text {mean }}\right)$, denoted by empirical $\delta p_{\text {mean }}$. And the empirical $\delta p_{\text {mean }}$ is compared with theoretical and experimental $\delta p_{\text {mean }}$. According to the gas state equation, the ignition pressure empirical formula can be expressed as:

$$
p_{i} V_{0}=\left(1-\mathrm{Y}_{\mathrm{P}}\right) M_{i} \frac{R T_{i}}{m_{g}}
$$

where, $T_{i}$ is the temperature of ignition gas, $M_{i}$ is the ignition charge weight, and $m_{g}$ is the molar mass of gas phase, and $Y_{P}$ is the mass fraction of condensed phase, which is equal to 0.46 . When the BP weight is fixed, the empirical $\delta p_{\text {mean }}$ is a constant.

Firstly, the theoretical mean pressure history and the experimental mean pressure history are compared, as shown in Fig. 8. Fig. 8 (a) is the comparison of global mean pressure history. In general, the theoretical curve shows an agreement with the experimental curve. Before the first pulse, the experimental initial equilibrium pressure of T-burner is about $11.89 \mathrm{MPa}$, and the theoretical initial equilibrium pressure of T-burner is about 11.56 MPa. The difference between experimental value and theoretical value is $0.33 \mathrm{MPa}$. Before the second pulse, the experimental equilibrium pressure is about $11.35 \mathrm{MPa}$, and the theoretical 
equilibrium pressure is about $11.68 \mathrm{MPa}$. The difference between experimental value and theoretical value is $-0.32 \mathrm{MPa}$. Both of these differences are within acceptable limits.

Secondly, Fig. 8 (b) is the detail of the first pulses comparison. The experimental curve can be divided into three segments by the variation of mean pressure gradient. Similarly, the theoretical curve also can be divided into three segments. The segmentation point of theoretical curve is closer to the coordinate origin. The pressure slope of first segment in experimental curve is about $39 \mathrm{MPa} / \mathrm{s}$, while that in theoretical curve is about $50 \mathrm{MPa} / \mathrm{s}$. The slope of theoretical curve is larger than that of experimental curve in the first segment. The pressure slope of second segment in experimental curve is about $1.762 \mathrm{MPa} / \mathrm{s}$, while that in theoretical curve is about $2.09 \mathrm{MPa} / \mathrm{s}$. Also, the slope of theoretical curve is larger than that of experimental curve in the second segment. The results indicate that the experimental burning time of BP is larger than the theoretical one, and the corresponding experimental mass flow rate of BP is less that the theoretical one. This is caused by the assuming of all particles ignited at the same time in the theoretical analysis. The mean pressure increment ( $\left.\delta p_{\text {mean }}\right)$ of experimental curve is equal to $0.91 \mathrm{MPa}$, and that of theoretical curve is about $0.89 \mathrm{MPa}$. For the first pulse, the theoretical $\delta p_{\text {mean }}$ is larger than the experimental $\delta p_{\text {mean }}$ with the error $-2.25 \%$. The results indicate that assuming of all particles ignited has little effect on the calculated mean pressure increment.
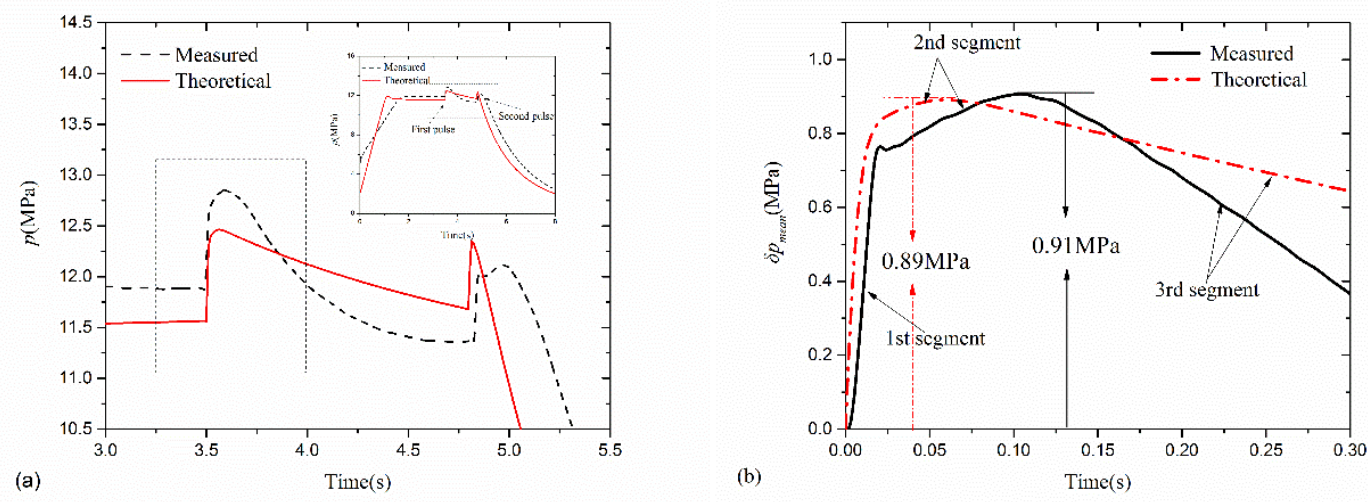

Fig. 8 Comparison of experimental and theoretical mean pressure history. 
Thirdly, theoretical $\delta p_{\text {mean }}$, experimental $\delta p_{\text {mean }}$ and empirical $\delta p_{\text {mean }}$ are compared, as shown in Table 8. For the first pulse, theoretical $\delta p_{\text {mean }}$ is $0.89 \mathrm{MPa}$, the empirical $\delta p_{\text {mean }}$ is $0.77 \mathrm{MPa}$, and experimental $\delta p_{\text {mean }}$ is $0.91 \mathrm{MPa}$. For the second pulse, theoretical $\delta p_{\text {mean }}$ is $0.76 \mathrm{MPa}$, the empirical $\delta p_{\text {mean }}$ is also $0.77 \mathrm{MPa}$, and experimental $\delta p_{\text {mean }}$ is $0.75 \mathrm{MPa}$. In general, the three values show an agreement with each other. For the first pulse, the error of the theoretical value is about $-2.25 \%$. For the second pulse, the error of the theoretical value is about $-1.32 \%$. It indicates that the theoretical analysis of mean pressure is reasonable. And the accuracy of Eq. (32) is about 95\%. In addition, the results show that the mean pressure increment of second pulse is much smaller than that of first pulse both in experimental and theoretical curves. It indicates that the mean pressure increment is greatly affected by the change of propellant burning surface.

Table 8 Comparisons of theoretical, empirical and experimental mean pressure increment.

\begin{tabular}{cccc}
\hline Pulse Number & Theoretical $\delta p_{\text {mean }} / \mathrm{MPa}$ & Empirical $\delta p_{\text {mean }} / \mathrm{MPa}$ & Measured $\delta p_{\text {mean }} / \mathrm{MPa}$ \\
\hline $1^{\text {st }}$ & 0.89 & 0.77 & 0.91 \\
$2^{\text {nd }}$ & 0.76 & 0.77 & 0.75 \\
\hline
\end{tabular}

\section{$5 \quad$ Results and discussions}

In above discussion, the theoretical models are established to estimate the pulse characteristics of BP. And the models are verified by T-burner experiments. In following discussion, based on the theoretical models, the influence of BP on pulse characteristics will be analyzed in detail. The main content is divided into four parts. The first part is the effect of BP burning rate. The second part is the effect of initial particle diameter of BP. The third part is the effect of BP weight. The fourth part is the summary of pulse characteristics of BP. The T-burner involved in following discussion is consistent with the T-burner employed in verification experiments. 


\subsection{The effect of BP burning rate}

In this part, the weight and initial particle diameter of BP are fixed, and the burning rate changes within a certain range. The BP weight is $50 \mathrm{~g}$. The initial particle diameter of $\mathrm{BP}$ is $5 \mathrm{~mm}$. The range of burning rate is $20 \sim 100 \mathrm{~mm} / \mathrm{s}$. Variations of mass flow rate with time are plotted in Fig. 9. When the burning rate of BP increases from $20 \mathrm{~mm} / \mathrm{s}$ to $100 \mathrm{~mm} / \mathrm{s}$, the initial mass flow rate increases from $1.2 \mathrm{~kg} / \mathrm{s}$ to $5.8 \mathrm{~kg} / \mathrm{s}$, and the burning time decreases from $0.1 \mathrm{~s}$ to $0.025 \mathrm{~s}$. As the burning rate increases, the mass flow changes more intensely within the burning process. The shaded area highlights the mass flow rates within pulse build-up time threshold. The integral of this part is the effective weight of $\mathrm{BP}\left(m_{b, e}\right)$. The values of $m_{b, e}$ are shown in Table 9. The results show that the effective weight of BP increases with the increasing burning rate of BP. In addition, compared with the burning times of BP, pulse build-up time threshold is a small value. Therefore, compared with the weight of BP (50 g), the effective weights of BP (1.9 g 8.91 g) are small values.

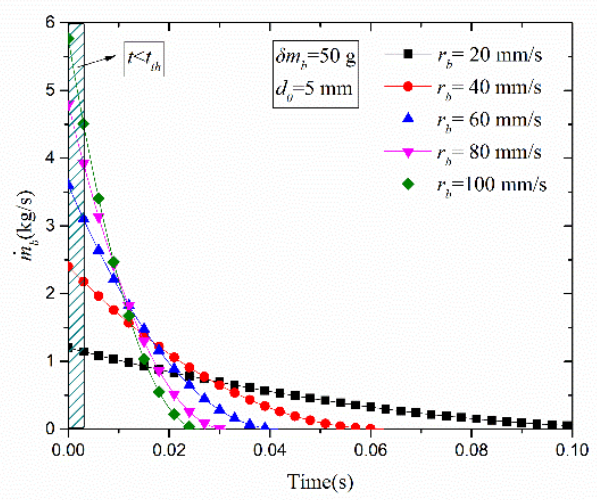

Fig. 9 The history of mass flow rate with different burning rates.

Table 9 Effective weights of BP with different burning rates.

\begin{tabular}{cccccc}
\hline$r_{b}(\mathrm{~mm} / \mathrm{s})$ & 20 & 40 & 60 & 80 & 100 \\
\hline$m_{b, e}(\mathrm{~g})$ & 1.90 & 3.76 & 5.57 & 7.34 & 8.91 \\
\hline
\end{tabular}


With the same range of burning rate, the variation of pressure pulse $(\delta p)$ and effective weight fraction ( $\eta$ ) are shown in Fig. 10. When the burning rate of BP increases from $20 \mathrm{~mm} / \mathrm{s}$ to $100 \mathrm{~mm} / \mathrm{s}$, the effective weight fraction increases from 0.04 to 0.18 , and pressure pulse increases from $0.08 \mathrm{MPa}$ to $0.42 \mathrm{MPa}$, which are the same as the law of effective weight of BP. It indicates that the effect of burning rate on the effective weight of $\mathrm{BP}$, effective weight fraction of $\mathrm{BP}$ and pressure pulse is the same. Increasing the burning rate of $\mathrm{BP}$ can increase all the three parameters.

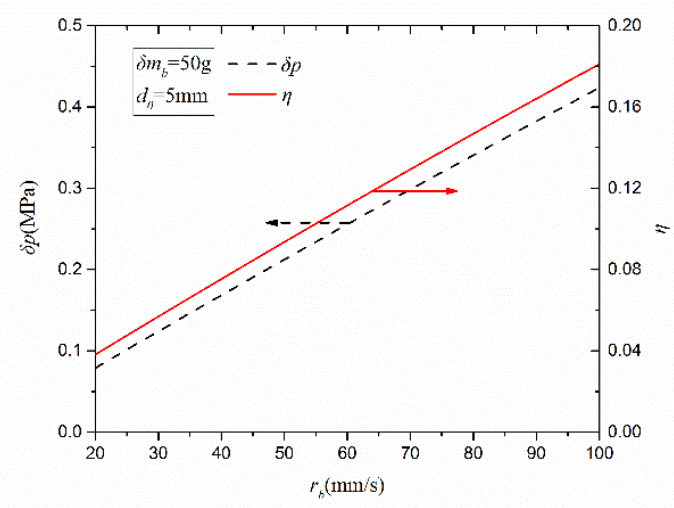

Fig. 10 Pressure pulse and effective weight fraction change with burning rate.

The calculated mean pressure history with different burning rates are shown in Fig. 11. The curves can be divided into two segments, ascending and descending segments. The ordinate of segmentation point represents the mean pressure increment $\left(\delta p_{\text {mean }}\right)$. The mean pressure increments $\left(\delta p_{\text {mean }}\right)$ of $20 \sim 100$ $\mathrm{mm} / \mathrm{s}$-cases are $0.801 \mathrm{MPa}, 0.854 \mathrm{MPa}, 0.873 \mathrm{MPa}, 0.887 \mathrm{MPa}$ and $0.891 \mathrm{MPa}$ in turns. The results show that $\delta p_{\text {mean }}$ increases with the increasing burning rate nonlinearly. The possible reason is that as the burning rate of $\mathrm{BP}$ increases, the burning time of $\mathrm{BP}$ decreases. And the action of nozzle on $\delta p_{\text {mean }}$ decreases, which is nonlinear. Then $\delta p_{\text {mean }}$ increases nonlinearly. In addition, as the burning time of BP decreases, the abscissa of segmentation points obviously shifted to zero. 


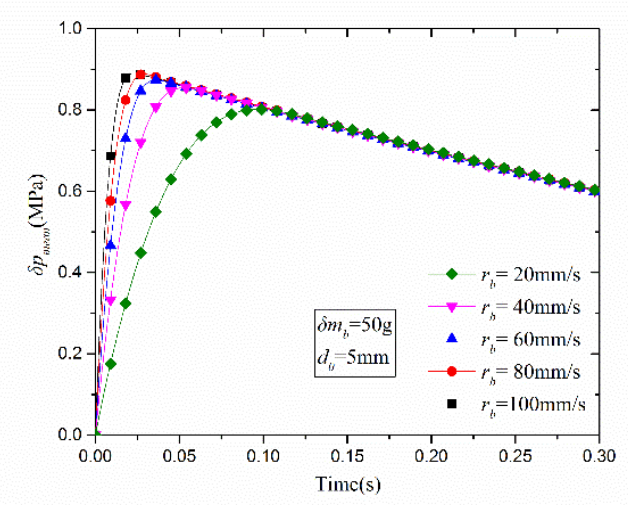

Fig. 11 The history of mean pressure with different burning rates.

\subsection{The effect of initial particle diameter of BP}

In this part, the weight and burning rate of BP are fixed, and the initial particle diameter changes within a certain range. The BP weight is $50 \mathrm{~g}$. The burning rate of BP is $50 \mathrm{~mm} / \mathrm{s}$. The range of initial particle diameter is $1 \sim 10 \mathrm{~mm}$. Variations of mass flow rate with time are plotted in Fig. 12. When the initial particle diameters increase from $2 \mathrm{~mm}$ to $10 \mathrm{~mm}$, the initial mass flow rates decrease from $7.5 \mathrm{~kg} / \mathrm{s}$ to 1.5 $\mathrm{kg} / \mathrm{s}$, and the burning times increase from $0.02 \mathrm{~s}$ to $0.1 \mathrm{~s}$. As the initial particle diameter increases, the change trend of mass flow rate is more gently. Likewise, the shaded area highlights the mass flow rate within pulse build-up time threshold. The integral of this part is the effective weight of BP. The values of $m_{b, e}$ are shown in Table 10. The results show that the effective weight of BP increases with the decreasing initial particle diameter of BP. 


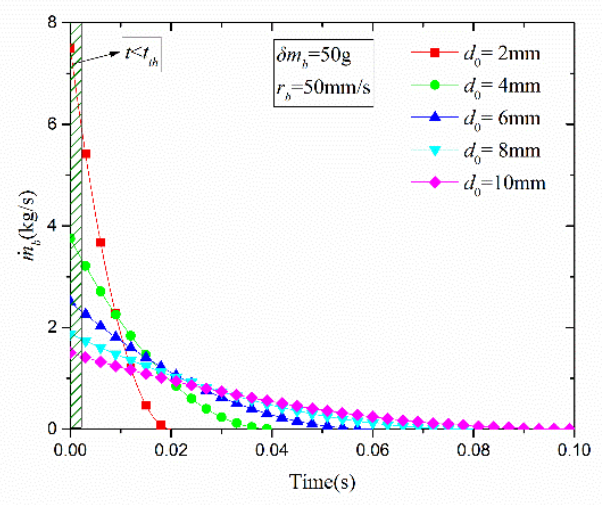

Fig. 12 The history of mass flow rate with different initial particle diameters.

Table 10 Effective weights of BP with different initial particle diameters.

\begin{tabular}{cccccc}
\hline$d(\mathrm{~mm})$ & 2 & 4 & 6 & 8 & 10 \\
\hline$m_{b, e}(\mathrm{~g})$ & 11.1 & 5.7 & 3.9 & 2.9 & 2.3 \\
\hline
\end{tabular}

With the same range of initial particle diameter, the variation of pressure pulse $(\delta p)$ and effective weight fraction $(\eta)$ are shown in Fig. 13. When initial particle diameters increase from $1 \mathrm{~mm}$ to10 mm, the effective weight fraction decreases from 0.7 to 0.05 , and pressure pulse decreases from $0.974 \mathrm{MPa}$ to $0.101 \mathrm{MPa}$. The peak of pressure pulse is inversely proportional to initial particle diameter of BP, which are the same as the law of effective weight of BP. It indicates that the effect of initial particle diameter on the effective weight of BP, effective weight fraction of BP and pressure pulse is the same. Decreasing the initial particle diameter of BP can increase all the three parameters. 


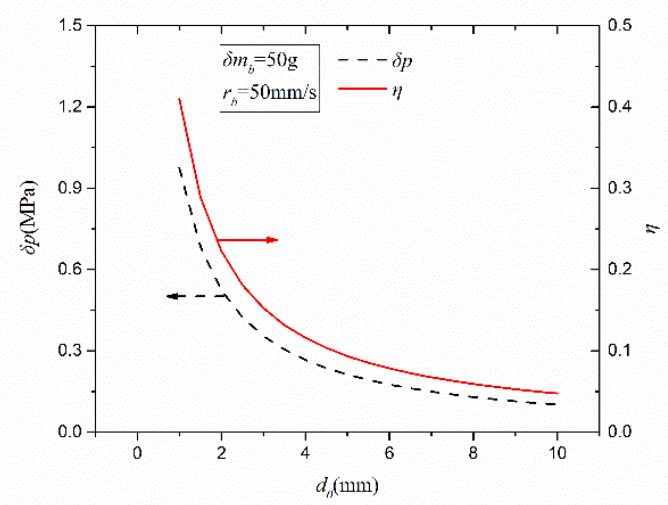

Fig. 13 Pressure pulse and effective weight fraction changed with initial particle diameter.

The calculated mean pressure history with different initial particle diameters are shown in Fig. 14. The curves can be divided into two segments too. The ordinate of segmentation point represents the mean pressure increment $\left(\delta p_{\text {mean }}\right)$. The mean pressure increments $\left(\delta p_{\text {mean }}\right)$ of $4 \sim 10 \mathrm{~mm}$-cases are $0.891 \mathrm{MPa}$, $0.875 \mathrm{MPa}, 0.856 \mathrm{MPa}, 0.839 \mathrm{MPa}$ and $0.822 \mathrm{MPa}$ in turns. The results show that $\delta p_{\text {mean }}$ decrease with the increasing initial particle diameters, nonlinearly. The main reason is the burning time of BP increases as the initial particle diameter increases. And the action of nozzle on $\delta p_{\text {mean }}$ increases nonlinearly. Then $\delta p_{\text {mean }}$ decreases nonlinearly. In addition, as the burning time of BP increases, the abscissa of segmentation points obviously shifted to $+\mathrm{x}$.

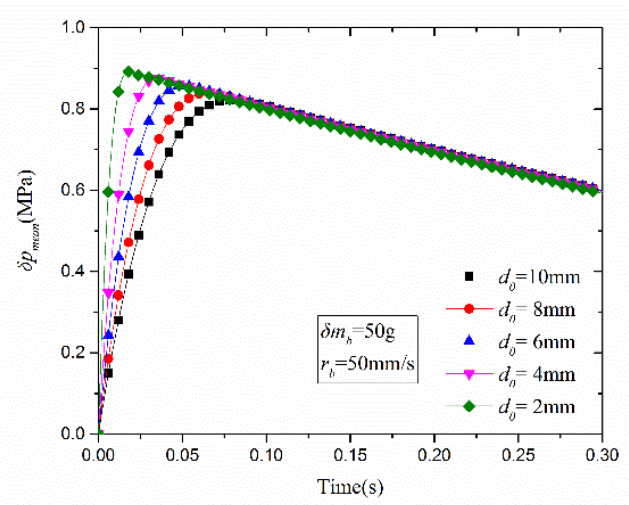

Fig. 14 The history of mean pressure with different initial particle diameters. 


\subsection{The effect of BP weight}

In this part, the initial particle diameter and burning rate of BP are fixed, and BP weight changes within a certain range. The initial particle diameter is $5 \mathrm{~mm}$. The burning rate is $50 \mathrm{~mm} / \mathrm{s}$. The range of BP weight is $10 \sim 70$ g. Variations of mass flow rate with time are plotted in Fig. 15. When BP weight increases from $10 \mathrm{~g}$ to $70 \mathrm{~g}$, the initial mass flow rates increase from $0.75 \mathrm{~kg} / \mathrm{s}$ to $4.25 \mathrm{~kg} / \mathrm{s}$, and the burning times are kept as a constant. The trend of mass flow rate did not change with BP weight. Likewise, the shaded area highlights the mass flow rate within pulse build-up time threshold. The integral of this part is the effective weight of BP. The values of $m_{b, e}$ are shown in Table 11. The result shows that the effective weight of BP increases with the increasing BP weight linearly.

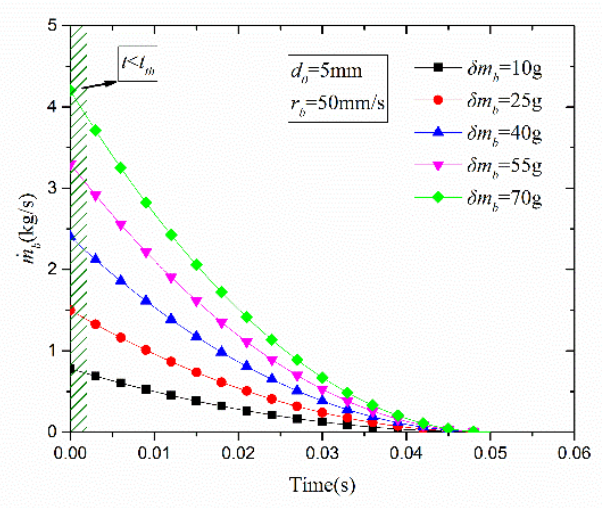

Fig. 15 The history of mass flow rate with different BP weights.

Table 11 Effective weights of BP with different BP weights.

\begin{tabular}{cccccc}
\hline$\delta m_{b}(\mathrm{~g})$ & 10 & 25 & 40 & 55 & 70 \\
\hline$m_{b, e}(\mathrm{~g})$ & 0.93 & 2.34 & 3.74 & 5.14 & 6.54 \\
\hline
\end{tabular}

With the same range of BP weight, variations of pressure pulse and effective weight fraction are shown in Fig. 16. When BP weight increases from $10 \mathrm{~g}$ to $70 \mathrm{~g}$, the pressure pulse increases from $0.03 \mathrm{MPa}$ to 0.3 MPa, linearly, which is the same as the law of effective weight of BP. However, the effective weight 
fraction is approximately equal to a constant. It indicates that effective weight fraction is independent on BP weight, and affected by burning time of BP only. Increasing BP weight can increase pressure pulse, linearly.

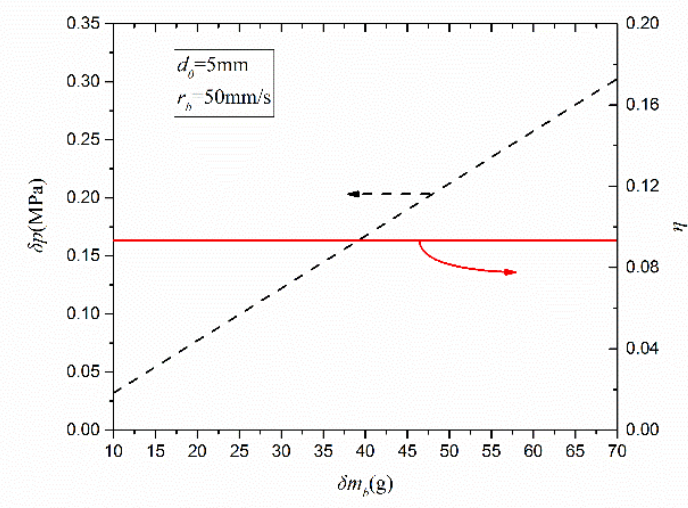

Fig. 16 Pressure pulse and effective weight fraction changed with BP weight.

The calculated mean pressure history with different BP weights are shown in Fig. 17. The curves can be divided into two segments too. The ordinate of segmentation point represents the mean pressure increment $\left(\delta p_{\text {mean }}\right)$. The mean pressure increments $\left(\delta p_{\text {mean }}\right)$ of $10 \sim 70$ g-cases are $0.143 \mathrm{MPa}, 0.413 \mathrm{MPa}, 0.684$ $\mathrm{MPa}, 0.956 \mathrm{MPa}$ and $1.228 \mathrm{MPa}$ in turns. The results show that $\delta p_{\text {mean }}$ increase with the increasing BP weight, linearly. In addition, the segmentation points do not shift with the increasing BP weight.

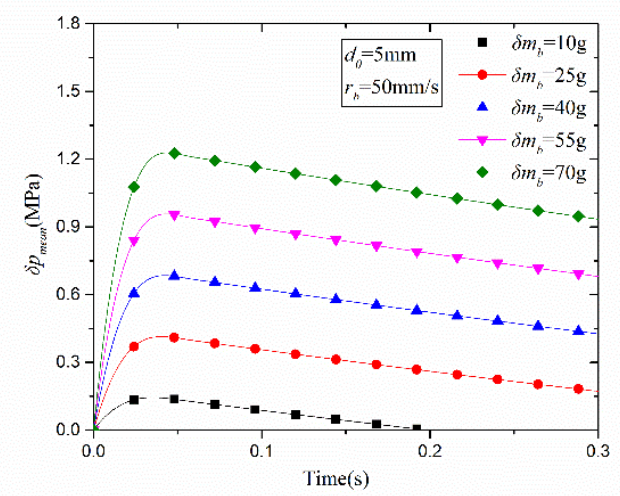

Fig. 17 The history of mean pressure with different BP weight. 


\subsection{Summary of pulse characteristics of BP}

Pulse characteristics is reflected in two aspects. One is pressure pulse, as $\delta p$. The other one is the mean pressure increment, as $\delta p_{\text {mean }}$. Burning properties of BP can be described by two parameters, burning time of $\mathrm{BP}$ and $\mathrm{BP}$ weight. According to section 3.1, burning time of $\mathrm{BP}$ is independent on $\mathrm{BP}$ weight. Pulse build-up time threshold $\left(t_{t h}\right)$ is the other key parameter, which decides the effective weight fraction of BP and the volume coefficient. A dimensionless parameter $\left(t_{b} / t_{t h}\right)$ is introduced to describe the relationship between burning time of BP and pulse build-up time threshold.

The pressure pulse change with $t_{b} / t_{t h}$ and BP weight is shown as Fig. 18. When $t_{b} / t_{t h}$ is smaller than 1 , the $\log _{10}(\delta p)$ is inversely proportional to $\log _{10}\left(t_{b} / t_{t h}\right)$. When $t_{b} / t_{t h}$ is larger than $1, \log _{10}(\delta p)$ decreases with the increasing $\log _{10}\left(t_{b} / t_{t h}\right)$, nonlinearly. There are five BP weights in the discussion, such as $10 \mathrm{~g}, 20 \mathrm{~g}, 30 \mathrm{~g}$, $40 \mathrm{~g}$ and $50 \mathrm{~g}$. The curve of each BP weight is parallel to others. And the values of pressure pulse increases with the increasing BP weight, linearly. The minimum diameter of BP is about $1 \mathrm{~mm}$. The corresponding minimum burning time of $\mathrm{BP}$ is about $10 \mathrm{~ms}$, which is 6 times of pulse build-up time threshold. The approximate range of pressure pulse produced by BP is shown by dotted line in Fig. 18.

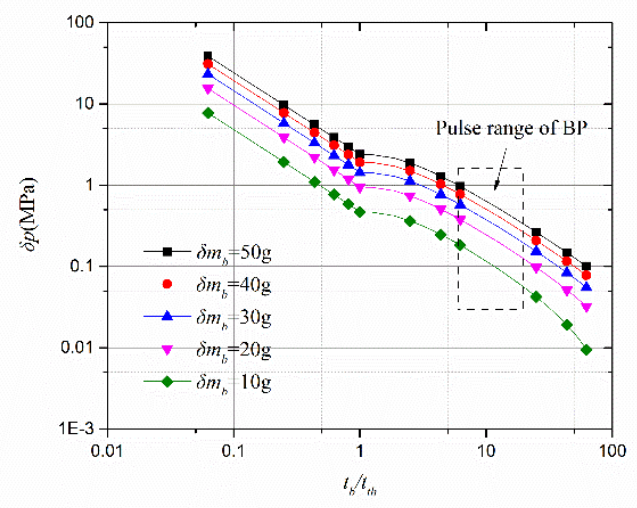

Fig. 18 Pressure pulse changed with $t_{b} / t_{t h}$ and BP weight. 
The mean pressure increments change with weight and burning time of BP are shown in Fig. 19. There are five BP weights in the discussion, such as $10 \mathrm{~g}, 20 \mathrm{~g}, 30 \mathrm{~g}, 40 \mathrm{~g}$ and $50 \mathrm{~g}$. For each BP weight, the mean pressure increment has a maximum. The maximums of mean pressure increment of $10 \sim 50 \mathrm{~g} \mathrm{BP}$ weights are $0.157 \mathrm{MPa}, 0.346 \mathrm{MPa}, 0.56 \mathrm{MPa}, 0.737 \mathrm{MPa}$ and $0.919 \mathrm{MPa}$, respectively. The maximum of mean pressure increment are approximately equidistant. And the curve of each BP weight is parallel to others. This indicates that values of mean pressure increment increase with the increasing BP weight approximately linearly. As the burning time of BP increases, the mean pressure increment decreases nonlinearly. This is because the action of nozzle increases with the increasing burning time of BP. When the BP weight is fixed, the mean pressure increment is changed by exhaust of nozzle.

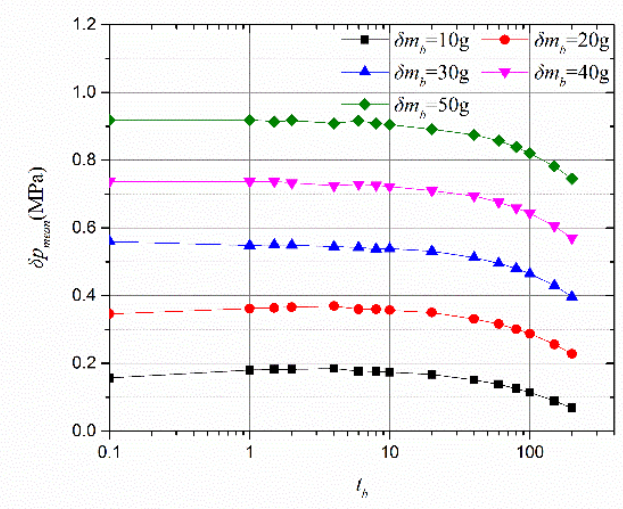

Fig. 19 Mean pressure increments changed with weight and burning time of BP.

\section{Conclusions}

In the present work, characteristics of pulse excitation in T-burners are studied experimentally and theoretically. The experimental pressure history of pulse excitation is analyzed. The parameters describing pulse excitation are introduced. The theoretical models are established to predict the pulse characteristic of BP in T-burners. The geometry of T-burner, burning properties of BP and influences of gas phase parameter 
are considered in models. Zero-dimensional and one-dimensional models are built to predict the pressure pulse. Using volume coefficient $\beta$, zero-dimensional model of T-burner is changed to zero-dimensional model of pulse control body, which is called as the modified zero-dimensional of pressure pulse. And the results of modified zero-dimensional model and one-dimensional model are very close. This indicates that modified zero-dimensional model can accurately predict the pressure pulse. The prediction model of mean pressure is zero-dimensional. The influences of burning properties of BP on pressure peak and mean pressure are studied in detail. The changing laws of pressure pulse and mean pressure are revealed. The influence mechanisms of BP on pulse characteristics are summarized. The results are as follows:

a) Burning properties of $\mathrm{BP}$ can be represented by burning time of $\mathrm{BP}$ and $\mathrm{BP}$ weight. Burning time of $\mathrm{BP}$ is independent of $\mathrm{BP}$ weight.

b) Pulse build-up time threshold $\left(t_{t h}\right)$ is the other key parameter, which decides the values of effective weight fraction of $\mathrm{BP}(\eta)$ and volume coefficient $(\beta)$. When $t_{b}>t_{t h}$, there are $\beta=2$ and $\eta<1$. The pressure pulse is approximately linear correlation with volume coefficient and BP weight. When $t_{b}<t_{t h}$, there are $\beta>2$ and $\eta=1$. The pressure pulse is approximately linear correlation with volume coefficient and BP weight.

c) Both pressure pulse and mean pressure increment increase with the weight of BP linearly. Pressure pulse is more sensitivity to the changing of burning time of BP. As the burning time of BP decreases, the mean pressure increment gradually increase to the maximum. For each weight of BP, when $\mathrm{BP}$ weight is $50 \mathrm{~g}$, the maximum of mean pressure increment is about $0.919 \mathrm{MPa}$. However, pressure pulse can be infinite in theory. 


\section{Acknowledgments}

This work is supported by the National Science Foundation of China (No. 1157020941). Y.Q. Liu, X.D.

Zhu, W.T. Wang and C. Peng are greatly acknowledged for their hard work on the experiments. J. Gao and

M. Feng are greatly acknowledged for their hard work on the correction and modification.

\section{References}

[1] W.S. Sun, Combustion Instabilities in Solid Rocket Motors (in Chinese), Beijing Institute of Technology Press, Beijing, China, 1988.

[2] F. Richecoeur, S. Ducruix, P. Scouflaire, S. Candel, Experimental investigation of high-frequency combustion instabilities in liquid rocket engine, Acta Astronautica, 62 (2008) 18-27.

[3] L. Yuan, C. Shen, Computational investigation on combustion instabilities in a rocket combustor, Acta Astronautica, 127 (2016) 634-643.

[4] H. Zhang, Y. Ga, B. Wang, X. Wang, Analysis of combustion instability via constant volume combustion in a LOX/RP-1 bipropellant liquid rocket engine, Science China Technological Sciences, 55 (2012) 1066-1077.

[5] W.X. Su, N.F. Wang, J.W. Li, Y.D. Zhao, M. Yan, Improved method of measuring pressure coupled response for composite solid propellants, Journal of Sound and Vibration, 333 (2014) 2226-2240.

[6] F. Vuillot, Vortex-shedding phenomena in solid rocket motors, Journal of Propulsion and Power, 11 (1995) 626-639.

[7] S. Gallier, F. Godfroy, Aluminum combustion criven instabilities in solid rocket motors, Journal of Propulsion and Power, 25 (2009) 509-521.

[8] F.E.C. Culick, Non-linear growth and limiting amplitude of acoustic oscillations in combustion chambers, Combustion Science and Technology, 3 (1971) 1-16.

[9] F.E.C. Culick, Non-Linear Growth and Limiting Amplitude of Acoustic Oscillations in Combustion Chambers, Combustion Science and Technology, 3 (2007) 1-16.

[10] J.E. Crump, Combustion instability testing of NASA BSM propellant (UTP 19048) in the NWC T-Burner, in, Naval Weapons Center, 1976.

[11] M. Golafshani, M. Farshchi, H. Ghassemi, Effects of grain geometry on pulse-triggered combustion instability in rocket motors, Journal of Propulsion and Power, 18 (2002) 123-130.

[12] J.D. Baum, J.N. Levine, Numerical techniques for solving nonlinear instability problems in solid rocket motors, AIAA Journal, 20 (1982) 955-961.

[13] F.S. Blomshield, J.E. Crump, H.B. Mathes, R.A. Stalnaker, M.W. Beckstead, Stability testing of full-scale tactical motors, Journal of Propulsion and Power, 13 (1997) 349-355.

[14] G.A. Flandro, S.R. Fischbach, J. Majdalani, Nonlinear rocket motor stability prediction: Limit amplitude, triggering, and mean pressure shift, Physics of Fluids, 19 (2007) 094101.

[15] C.L. Oberg, Combustion stabilization with acoustic cavities, Journal of Spacecraft and Rockets, 8 (1971) 1220-1225.

[16] J. Spurling, F. Blomshield, D. Pate, Effects of temperature conditioned environment on a propellant's pressure-coupled response, in: 46th AIAA/ASME/SAE/ASEE Joint Propulsion Conference \& Exhibit, 
Nashville, TN, 2010.

[17] F. Blomshield, C. Bicker, R. Stalnaker, High pressure pulsed motor firing combustion instability investigations, in: 33rd AIAA Joint Propulsion Conference and Exhibit, Seattle, Washington State, 1997.

[18] W.S. Sun, J.M. Fang, X.W. Zhang, Y. Sui, J.M. Hu, A Pressure Controllable Burner, Acta Armamentarii of China, 3 (1987) 57-65.

[19] J.A. Murray, J.A. Condon, D.E. Krusch, Pulsing criteria for solid propellant rocket motors, in, Air Force Rocket Propulsion Lab., TR-79-45, Edwards AFB, CA., 1979.

[20] J.A. Murray, J.A. Condon, D.E. Krusch, Pulsing criteria for solid rocket motors volume II: motor pulsing design manuals, in, Air Force Rocket Propulsion Lab., TR-79-45, Edwards AFB, CA., 1981.

[21] J. Baum, R. Lovine, J. Levine, Pulsing of solid propellant rocket motors: A numerical and experimental study, in: AlAA 20th Aerospace Sciences Meeting, Orlando, Florida, 1982.

[22] J.D. Baum, R.L. Lovine, J.N. Levine, Pulsing techniques for solid-propellant rocket motors - Modeling andcold-flow testing, Journal of Spacecraft and Rockets, 20 (1983) 150-157.

[23] J.D. Baum, J.N. Levinet, R.L. Lovine, Pulse-triggered instability in solid rocket motors, AIAA Journal, 22 (1984) 1413-1419.

[24] J.D. Baum, J.N. Levine, R.L. Lovine, Pulsed instability in rocket motors - A comparison between predictions and experiments, Journal of Propulsion and Power, 4 (1988) 308-316.

[25] R.L. Lovine, J.D. Baum, J.N. Levine, Ejecta pulsing of subscale solid propellant rocket motors, AIAA Journal, 23 (1985) 416-423.

[26] R.S. Brown, Blowdown pulser design criteria for solid-propellant rockets, Journal of Propulsion and Power, 2 (1986) 110-116.

[27] N.N. Smirnov, Combustion of porous dispersing fuels, Combustion, Explosion, and Shock Waves, 27 (1991) $52-58$.

[28] N.N. Smirnov, S.I. Safargulova, Propagation of weak disturbances in the combustion of compressible porous fuels, Combustion, Explosion, and Shock Waves 27 (1991) 154-161.

[29] N.N. Smirnov, I.D. Dimitrienko, Convective combustion of porous compressible propellants, Combustion and Flame, 89 (1992) 260-270.

[30] D. Jin, Black Powder(In Chinese), National Defence Industry Press, Beijing, China, 1978.

[31] K.J. White, R.A. Sasse, Relationship of combustion characteristics and physical properties of black powder, in, US Army Armament Research and Development Command, Ballistic Research Laboratory, Memorandum Report ARBRL-MR-03219, November 1982.

[32] C.K. Law, H.K. Law, A d2-law for multicomponent droplet vaporization and combustion, AIAA Journal, 20 (1982) 522-527.

[33] V.R. Feldgun, Y.S. Karinski, I. Edri, D.Z. Yankelevsky, Prediction of the quasi-static pressure in confined and partially confined explosions and its application to blast response simulation of flexible structures, International Journal of Impact Engineering, 90 (2016) 46-60.

[34] H. Ren, Q. Cui, Q. Jiao, Thermal Decomposition and Kinetic Parameters of Black Powder Reaction, Chinese Journal of Energetic Materials 15 (2007) 29-32.

[35] M. Yan, J. Li, W. Su, N. Wang, Study on Pulse Triggering Combustion Instability in a Combustion Chamber, Energy Procedia, 61 (2014) 1130-1133.

[36] F.A. Williams, M. Barrere, N.C. Huang, Fundamental Aspects of Solid Propellant Rockets, Technivision Services, Slough, England, 1989. 